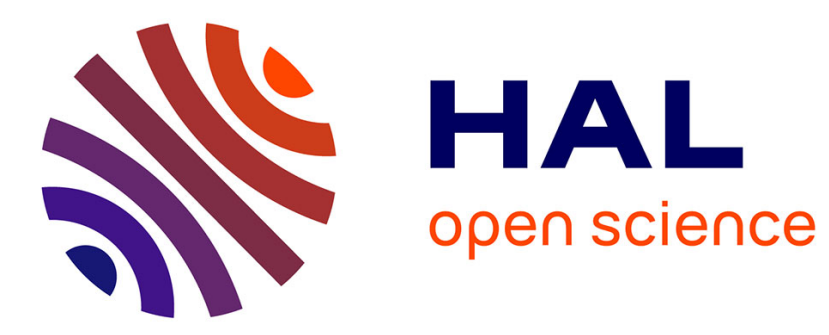

\title{
Conjugated Metallo-Supramolecular Polymers Containing a Phosphole Unit
}

Tereza Vitvarová, Jan Svoboda, Muriel Hissler, Jiří Vohlídal

\section{To cite this version:}

Tereza Vitvarová, Jan Svoboda, Muriel Hissler, Jiří Vohlídal. Conjugated Metallo-Supramolecular Polymers Containing a Phosphole Unit. Organometallics, 2017, 36 (4), pp.777-786. 10.1021/acs.organomet.6b00822 . hal-01468962

HAL Id: hal-01468962 https://hal-univ-rennes1.archives-ouvertes.fr/hal-01468962

Submitted on 16 Feb 2017

HAL is a multi-disciplinary open access archive for the deposit and dissemination of scientific research documents, whether they are published or not. The documents may come from teaching and research institutions in France or abroad, or from public or private research centers.
L'archive ouverte pluridisciplinaire HAL, est destinée au dépôt et à la diffusion de documents scientifiques de niveau recherche, publiés ou non, émanant des établissements d'enseignement et de recherche français ou étrangers, des laboratoires publics ou privés. 


\title{
Conjugated metallo-supramolecular polymers containing a phosphole unit
}

\author{
Tereza Vitvarováa ${ }^{\mathrm{a} b}$, Jan Svoboda ${ }^{\mathrm{b}}$, Muriel Hissler*a ${ }^{\mathrm{a}}$ and Jiří Vohlídal*b \\ ${ }^{a}$ Institut des Sciences Chimiques de Rennes, UMR6226 CNRS-Université de Rennes 1, Campus de Beaulieu, 35042 Rennes \\ Cedex, France. \\ ${ }^{\mathrm{b}}$ Charles University in Prague, Faculty of Science, Department of Physical and Macromolecular Chemistry, Hlavova 2030/8, \\ CZ-128 43 Prague, Czech Republic. \\ Supporting Information Placeholder
}

\begin{abstract}
A new building block, TPT, composed of the substituted phosphole ring surrounded by two thiophene rings with 2,2':6',2"-terpyridine-4'-yl (tpy) end-groups, is prepared and assembled with metal ions $\left(\mathrm{Co}^{2+}, \mathrm{Cu}^{2+}, \mathrm{Fe}^{2+}, \mathrm{Ni}^{2+}\right.$ and $\left.\mathrm{Zn}^{2+}\right)$ into metallo-supramolecular polymers (MSPs) and properties of both TPT and the MSPs are compared with those of their counterparts with terthiophene central blocks. A distinct red shift of the UV/vis band about 60 to $100 \mathrm{~nm}$ proves the decrease in the bandgap energy due to replacing the thiophene-2,5-diyl with a phosphole-2,5-diyl central unit, which is due to the lowered aromaticity of phosphole ring compared to the aromaticity of thiophene ring. Assembling of TPT with metal ions gives oligomeric chains comprising up to ten unimeric units in dilute solutions. MSPs with $\mathrm{Fe}^{2+}$ and $\mathrm{Ni}^{2+}$ ion couplers exhibit very slow constitutional dynamics, while those with $\mathrm{Cu}^{2+}$ and $\mathrm{Zn}^{2+}$ ion couplers quite fast constitutional dynamics. A metal to ligand charge transfer is observed only for $\mathrm{Fe}^{2+}-$ MSPs, while luminescence only for $\mathrm{Zn}^{2+}$-MSPs, mainly at an excess of $\mathrm{Zn}^{2+}$ ions, which indicates a positive effect of the endcapping of MSP chains with these ions.
\end{abstract}

\section{INTRODUCTION}

The development of semiconducting organic and organic/inorganic materials for applications in photovoltaics, lightemitting devices, field effect transistors and molecular electronics is an area of permanently high interest. ${ }^{1-3}$ Supramolecular chemistry based on the self-assembly of polymers from properly designed building blocks has become an efficient tool for the construction of soft functional materials having specific optical and/or redox properties. ${ }^{4}$ Metallo-supramolecular polymers (MSPs) based on building blocks with chelating end-groups linked to chains through reversible metal-ligand coordination represents an important class of soft organic/inorganic supramolecular materials. ${ }^{5,6}$ These macromolecular metal-containing systems may exhibit the properties of standard organic polymers (viscosity, processability, etc.), but the incorporation of metallic complexes in the polymer chain opens new perspectives giving access to magnetic, redox, optical, electrochromic, or specific mechanical properties; In addition, they can reversibly disassemble and reassemble at increased temperature in solution and exchange metal ions (ion couplers) and/or building blocks with other MSPs under these conditions leading to the development of environmentadaptable materials. ${ }^{7,8}$ Owing to their unique properties, MSPs are promising systems for the development of functional selforganized architectures with tunable properties.

The physical properties of these constitutionally dynamic coordination polymers or, in short, dynamers ${ }^{9}$ can be tuned by (i) the structure of central parts of their unimers, ${ }^{10}$ (ii) choice of their chelate end-groups (ion selectors), and (iii) choice of ions (ion couplers) connecting unimers species into chains. ${ }^{11,12}$ The most popular chelating end-group is the tridentate $2,2^{\prime}: 6^{\prime}, 2^{\prime \prime}$-terpyridine because it is able to form well-defined octahedral complexes with a wide range of transition metal cations. Furthermore, the structure of the central part of the unimer plays an important role since it can introduce a great variety of structural arrangements and/or physicochemical properties (e.g., viscosity, optical, mechanical properties, etc.) to the targeted metallo-polymer. For example, various conjugated MSPs have been prepared from linear unimers with oligophenylene $^{13-15}$, oligofluorene ${ }^{16-18}$ and oligothiophene ${ }^{19-24}$ central blocks capped with tridentate 2,2':6',2"-terpyridine-4'yl end-groups assembled with metal ions such as $\mathrm{Ru}^{2+}, \mathrm{Fe}^{2+}$, $\mathrm{Zn}^{2+}$ and $\mathrm{Co}^{2+} \cdot 11,12,25$ In general, central blocks of these unimers are composed of $\sigma$-bonded highly aromatic rings, which doesn't lead to an efficient delocalization of $\pi$-electrons along the whole molecule owing to the rather high autonomy of strongly aromatic systems. Hence the introduction of less aromatic conjugated rings into the unimer structure can be expected to give the desired unimers and MSPs with significantly decreased energy band-gaps. For this purpose, the phosphole ring is a good candidate since it possesses a weak aromaticity and a low-lying LUMO level. Effectively, the phosphorus atom in the ring namely adapts a pyramidal geometry $^{26}$ where its lone electron pair almost does not interact with the endocyclic diene $\pi$-electrons. Therefore, delocalization of electrons in a phosphole ring stems from the so called $\sigma-\pi$ hyperconjugation involving the exocyclic P-R $\sigma$-bond and the endocyclic diene $\pi$-system. ${ }^{27}$ As a result, phosphole is less aromatic compared to pyrrole and thiophene. ${ }^{28}$ Furthermore, mixed phosphole-thiophene derivatives are the most widely investigated phosphole based $\pi$-conjugated systems $s^{27,29-40}$ since $(i)$ this combination of heteroles allows to obtain low 1 
HOMO-LUMO gap derivatives due to maximized orbital interactions, (ii) a built in phosphole ring represents a new center for potential structural variations of such chains mainly by choice of the $\mathrm{P}$-atom substituent $\mathrm{R}$, and oxidation of the ring $\mathrm{P}$-atom (e.g., to $\mathrm{P}=\mathrm{S}$ or $\mathrm{P}=\mathrm{O}$ ), and (iii) it is possible to exploit the rich chemistry of thiophene to readily obtain novel derivatives via $\mathrm{Pd}$-catalyzed $\mathrm{C}$-C coupling reactions or electropolymerization. ${ }^{27,29,36,41}$

Considering these appealing functions of mixed phospholethiophene derivatives, there is a great interest for the development of unimers and MSPs based on mixed phospholethiophene structures in order to gain more insight into structure-property relationship and to further develop MSPs for specific applications.

MSPs composed of a unimer that comprises the phosphole2,5-diyl unit has not yet been reported. Only a simple complex of $\left[\mathrm{ZnL}_{2}\right]^{2+}$, where the ligand $\mathrm{L}$ is mono-tpy derivative of dithieno[3,2-b:2',3'-d]phosphole, has been reported by Bai et al. $^{42}$ Therefore, in order to examine the above-outlined idea, a new unimer composed of a substituted phosphole-2,5-diyl unit surrounded with two thiophene-2,5-diyl units capped with tpy end-groups has been prepared, characterized, and assembled with various metal ions $\left(\mathrm{Co}^{2+}, \mathrm{Cu}^{2+}, \mathrm{Fe}^{2+}, \mathrm{Ni}^{2+}\right.$ and $\left.\mathrm{Zn}^{2+}\right)$ into corresponding MSPs (Scheme 1). Optical spectral properties of this new phosphole unimer, hereafter denoted TPT, and from it derived MSPs are discussed and compared with the properties of recently reported related unimers (Chart 1) and MSPs with terthiophene central blocks. ${ }^{22}$
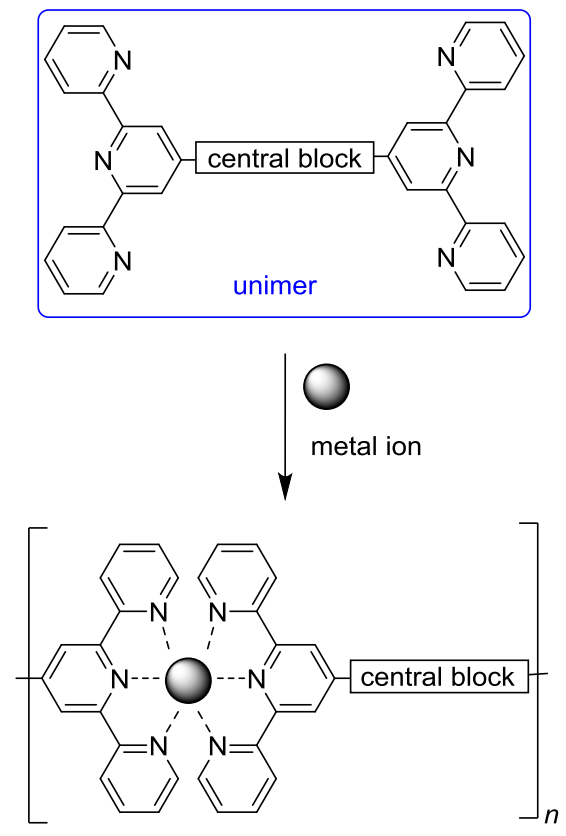

Scheme 1. Metallo-supramolecular polymerization of bisterpyridines
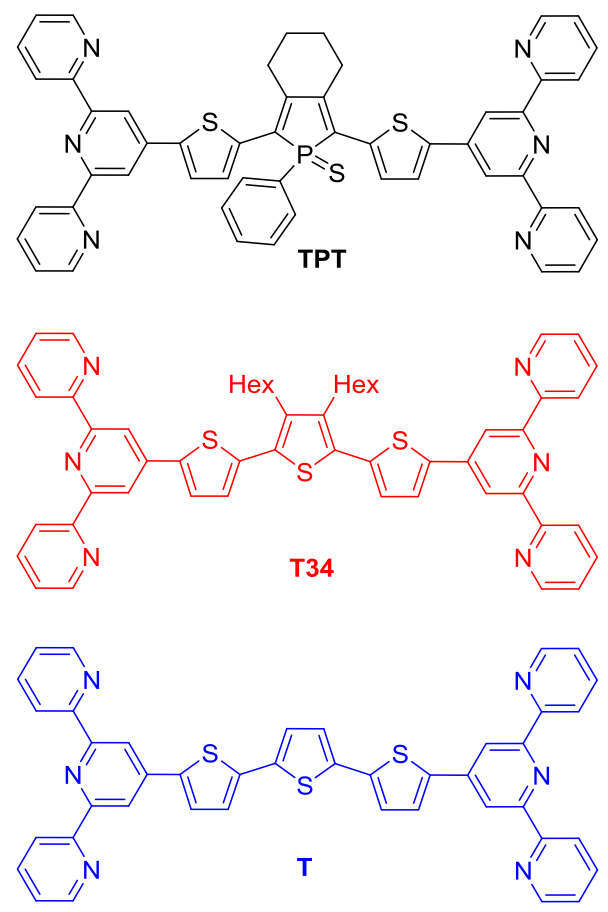

Chart 1. Structures of unimers under discussion

\section{RESULTS AND DISCUSSION}

\section{Synthesis of phosphole unimer TPT and its polymers}

The TPT unimer was synthesized from 1-phenyl-2,5bis(thiophen-2-yl)thioxophosphole (1) by attaching the tpy end-groups using a Suzuki coupling strategy (Scheme 2). The central block 1, which has been previously described, ${ }^{36}$ was borylated using a direct $\mathrm{C}-\mathrm{H}$ activation approach in the presence of an iridium catalyst ${ }^{43}$ (Scheme 2 ). The reaction conditions used for this $\mathrm{C}-\mathrm{H}$ reaction are those currently applied for the borylation of the thiophene ring. In addition, the reaction could be monitored by phosphorus NMR since the signals of the borylated species and starting molecule occur at slightly different chemical shifts $\left({ }^{31} \mathrm{P}\right.$ NMR: $\delta=+52.1 \mathrm{ppm}$ for compound 1 and +51.8 ppm for compound 2) (Scheme 2). When the characteristic chemical shift of compound $\mathbf{1}$ disappears, the mixture is diluted with dichloromethane $(20 \mathrm{~mL})$ and water $(20 \mathrm{~mL})$. The compound $\mathbf{2}$ is then isolated from the organic phase by evaporation of the organic solvent followed by reprecipitation. 


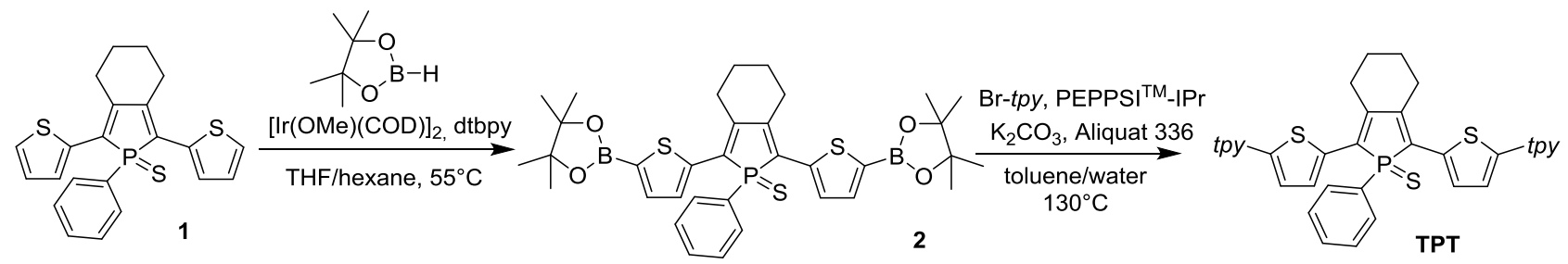

Scheme 2. Synthesis of unimer TPT

The $\alpha, \omega$-bis(borylated) central block 2 was then reacted with Br-tpy using modified Suzuki coupling conditions. The best yields were obtained using the PEPPSI ${ }^{\mathrm{TM}}$-IPr catalyst in a toluene/water $(1 / 1, \mathrm{v} / \mathrm{v})$ biphasic system in the presence of Aliquat 336 phase transfer catalyst and potassium carbonate (Scheme 2). Though the reaction mixture was kept at high temperature and in alkaline environment, the formation of a phospholene type side product, which can sometimes takes place at such temperatures, ${ }^{44}$ was not observed under the applied conditions. The unimer TPT was purified by column chromatography and isolated as an air-stable powder in modest yield (15\%). (For overall scheme of the synthesis see Scheme S1 in the Supporting Information).

Metallo-supramolecular polymers were prepared by spontaneous assembly of TPT with metal ions in a chloroform/acetonitrile solvent mixture (1/1 by vol.) at room temperature. A solution containing equimolar amounts of TPT and particular metal(II) ( $\mathrm{Fe}, \mathrm{Co}, \mathrm{Cu}, \mathrm{Ni}, \mathrm{Zn}$ ) perchlorate was allowed to equilibrate for one day and the formed MSP isolated by evaporation of solvents. Prepared MSPs are further denoted by abbreviations: P(TPT/Fe), P(TPT/Co), P(TPT/Cu), P(TPT/Ni) and P(TPT/Zn) or, in general, P(TPT/M) (Scheme 3) and their spectral characteristic are discussed below.
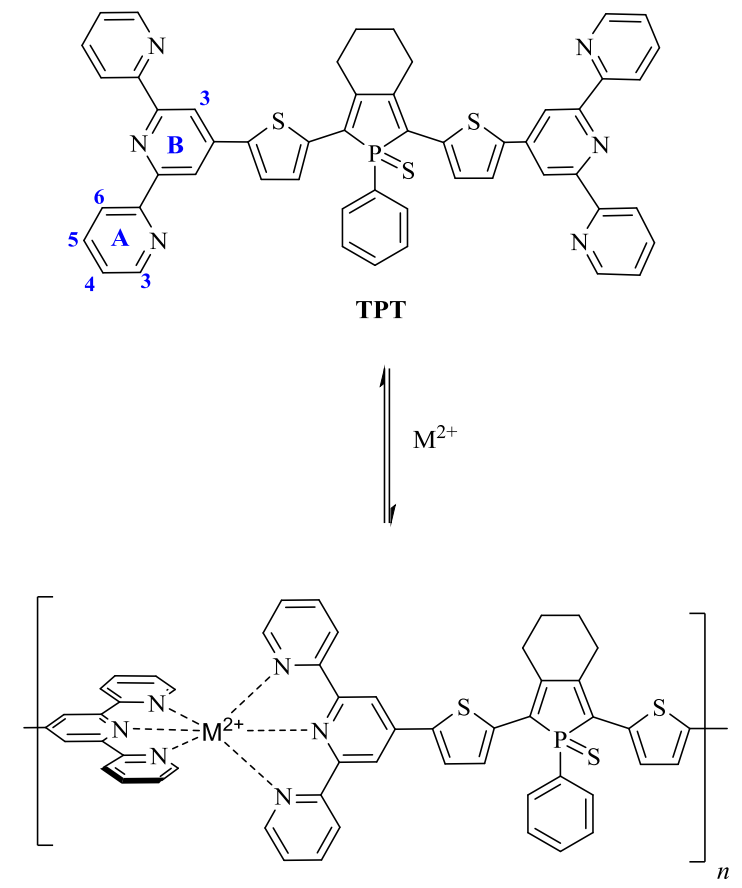

P(TPT/M), where $\mathrm{M}=\mathrm{Fe}, \mathrm{Co}, \mathrm{Ni}, \mathrm{Cu}, \mathrm{Zn}$

\section{Optical and redox properties of the unimer TPT}

In order to have an understanding of the characteristics of this novel $\pi$-conjugated unimer TPT, we studied its optical and electrochemical properties. The UV/vis absorption spectrum in solution of TPT (Figure 1a) shows a band centered at $281 \mathrm{~nm}$ that is mainly contributed by transitions in tpy end-groups ${ }^{45}$ and a band centered at $\lambda_{\mathrm{abs}}=481 \mathrm{~nm}$ that is contributed by HOMO to LUMO transitions that are spread over the unimer central block and adjacent central rings of tpy end-groups ${ }^{20}$ ${ }_{22,24,42,45}$ (see diagrams obtained by the DFT calculations, Figure S1). The fluorescence spectrum of TPT (Figure 1b) shows a structured emission band centered at $\lambda_{\mathrm{F}}=603 \mathrm{~nm}$. As expected, the presence of an extended $\pi$-conjugation in TPT induces a significant red-shift in the absorption and emission maxima compared to the corresponding bands of the central block without tpy end-groups $\left(\lambda_{\mathrm{abs}}=432 \mathrm{~nm} ; \lambda_{\mathrm{F}}=548 \mathrm{~nm}\right){ }^{34}$

Furthermore, the UV/vis as well as the luminescence band of TPT is substantially red shifted compared to the corresponding band of $\mathbf{T}$ as well as T34 (see also Table 1, Figure 1), two related terthiophene unimers possessing identical number of conjugated double bonds and similar structure, only the phosphole central ring is formally replaced by the unsubstituted (in unimer T) or dihexylated (T34) thiophene ring. These observations show a substantial decrease in the bandgap energy caused by replacing the middle high aromatic thiophene ring in the unimer central block with a low aromatic phosphole ring. The decreased energy bandgap of TPT was confirmed by cyclic voltammetry, $2.74 \mathrm{eV}$ for TPT and $3.08 \mathrm{eV}$ for $\mathbf{T}{ }^{21}$ The DFT calculations provided slightly lower band-gap energy values for both TPT $(2.62 \mathrm{eV})$ and $\mathbf{T}$ $(2.97 \mathrm{eV})$, but the same band-gap energy difference between TPT and $\mathbf{T}$ equal to ca $-0.25 \mathrm{eV}$. Comparing the thin film spectra of the unimers, TPT shows the main UV/vis band $\left(\lambda_{\text {abs }}=520 \mathrm{~nm}\right)$ considerably red shifted compared to the bands of T34 $\left(\lambda_{\mathrm{abs}}=455 \mathrm{~nm}\right)$ and $\mathbf{T}\left(\lambda_{\mathrm{abs}}=426 \mathrm{~nm}\right)$, thus confirming a decrease in the band-gap energy even in the thin film of TPT. (The fact that $\mathbf{T}$ shows $\lambda_{\text {abs }}$ lower than T34 has been explained by the damping of thermal twisting of thiophene rings by the attached hexyl groups which are partly anchored in solid films ${ }^{22}$ ). The observed red-shift in UV/vis might but need not directly relate to increased delocalization of electrons. The results of DFT calculations (Figure S1a) namely show that the HOMO of TPT is delocalized rather equally over all three central rings, while the LUMO is localized primarily on the phosphole ring with more minor contributions from thiophene rings. This indicates that the observed spectral red shift is very likely contributed by charge-transfer interactions within TPT molecules. 

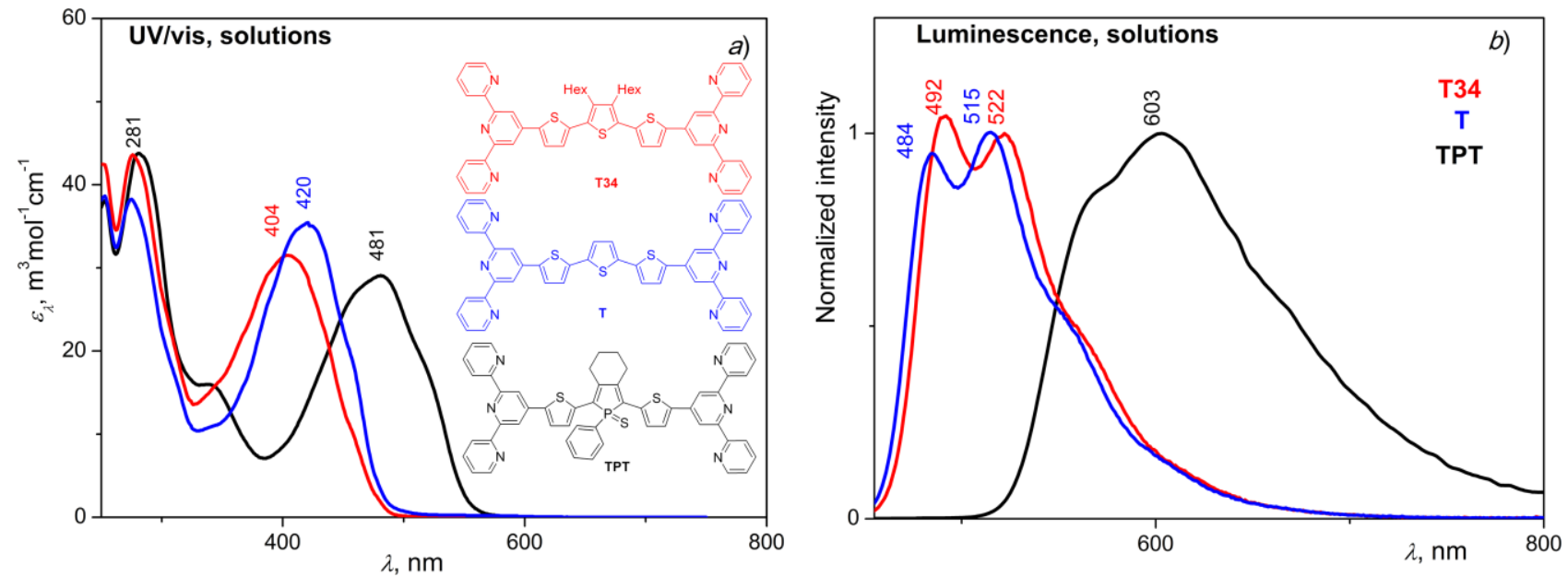

Figure 1. Solution UV/vis (a) and fluorescence (b) spectra of the phosphole unimer TPT and terthiophene unimers T, T34.

Table 1. Spectroscopic data for unimers TPT, T and T34 and related MSPs.

\begin{tabular}{|c|c|c|c|c|c|c|c|c|}
\hline & \multicolumn{2}{|l|}{$\lambda_{\mathrm{abs}}, \mathrm{nm}$} & \multicolumn{2}{|l|}{$\lambda_{\mathrm{F}}, \mathrm{nm}$} & \multicolumn{2}{|l|}{$\Phi, \%$} & \multicolumn{2}{|l|}{$\Delta v_{\mathrm{s}}, \mathrm{cm}^{-1}$} \\
\hline & solution & film & solution & film & solution & film & solution & film \\
\hline TPT & 482 & 520 & 603 & 685 & 19 & 0.7 & 4160 & 4630 \\
\hline P(TPT/Zn) & 507 & 509 & 634 & 641 & - & 0.5 & 3950 & 4100 \\
\hline P(TPT/Ni) & 509 & 526 & - & - & - & - & - & - \\
\hline $\mathbf{P}(\mathrm{TPT} / \mathrm{Cu})$ & 514 & 531 & - & - & - & - & - & - \\
\hline P(TPT/Co) & 529 & 554 & - & - & - & - & - & - \\
\hline P(TPT/Fe) & 491 & \multicolumn{3}{|c|}{$499\left(\lambda_{\mathrm{MLCT}}=625 \mathrm{~nm}\right)$} & - & - & - & - \\
\hline $\mathbf{T}$ & $420 *$ & 426 & $484 / 515^{*}$ & 730 & & & $3150 / 4390 *$ & 9780 \\
\hline T34 & $404 *$ & 455 & $492 / 522 *$ & 600 & & & $4430 / 5600^{*}$ & 5310 \\
\hline $\mathbf{P}(\mathrm{T} / \mathrm{Zn})$ & $479 *$ & $469 *$ & $635^{*}$ & $686^{*}$ & & & $5130 *$ & $6750 *$ \\
\hline P(T34/Zn) & $480 *$ & $495^{*}$ & $620 *$ & $640^{*}$ & & & $4700 *$ & $4600 *$ \\
\hline
\end{tabular}

Solvent chloroform/acetonitrile (1/1 by vol.); films casted on a quartz glass; $\Phi$ luminescence quantum efficiency; $\Delta v_{\mathrm{s}}$ Stokes shift calculated by formula: $1 / \lambda_{\mathrm{abs}}-1 / \lambda_{\mathrm{F}}$; *data taken from ref. ${ }^{22}$ (solutions in THF); $\lambda_{\mathrm{MLCT}}$ stands for the wavelength of the absorption maximum of the band of the metal-to-ligand charge transfer (MLCT) transitions (an electron transfer from a metal atom orbital to the ligand $\pi^{*}$ orbital). For a comparison, we provide here $\lambda_{\text {abs }}$ values for chloroform/acetonitrile solutions of $\left[\mathrm{M}(\mathbf{T}-t p y)_{2}\right]^{2+}$ complexes (where T-tpy stands for 4'-(2thienyl)-2,2':6',2"-terpyridine) of corresponding $\mathrm{M}^{2+}$ ions: $351 \mathrm{~nm}($ for $\mathrm{M}=\mathrm{Ni}), 352 \mathrm{~nm}(\mathrm{Cu}), 333 \mathrm{~nm}(\mathrm{Co})($ all our new data); $344 \mathrm{~nm}(\mathrm{Zn})$ and $320 \mathrm{~nm}\left(\mathrm{Fe} ; \lambda_{\mathrm{MLCT}}=551 \mathrm{~nm}\right)$, both from ref. ${ }^{45}$ 
The maximum of the thin film photoluminescence band of unimer TPT $\left(\lambda_{\mathrm{F}}=685 \mathrm{~nm}\right.$, see Figure S2) is red shifted compared to that of unimer T34 $\left(\lambda_{\mathrm{F}}=597 \mathrm{~nm}\right)$ but blue shifted compared to that of unimer $\mathbf{T}\left(\lambda_{\mathrm{F}}=731 \mathrm{~nm}\right)$, for which the Stokes shift approaches $10^{4} \mathrm{~cm}^{-1}$ (i.e., $1.24 \mathrm{eV}$; see Table 1). Such large Stokes shift proves extensive conformational relaxation of excited $\mathbf{T}$ molecules, which could be due to their regular packing in aggregates allowing so high relaxation, as it has been reported for oligothiophenes. ${ }^{46}$ Large Stokes shifts accompanied with low fluorescence quantum yields are typical of H-aggregates. ${ }^{47}$ To examine this hypothesis more in detail, the photoluminescence spectra of T, T34 and TPT were recorded on samples of unimers dispersed at various concentrations in $\mathrm{KBr}$ pellets as matrix.
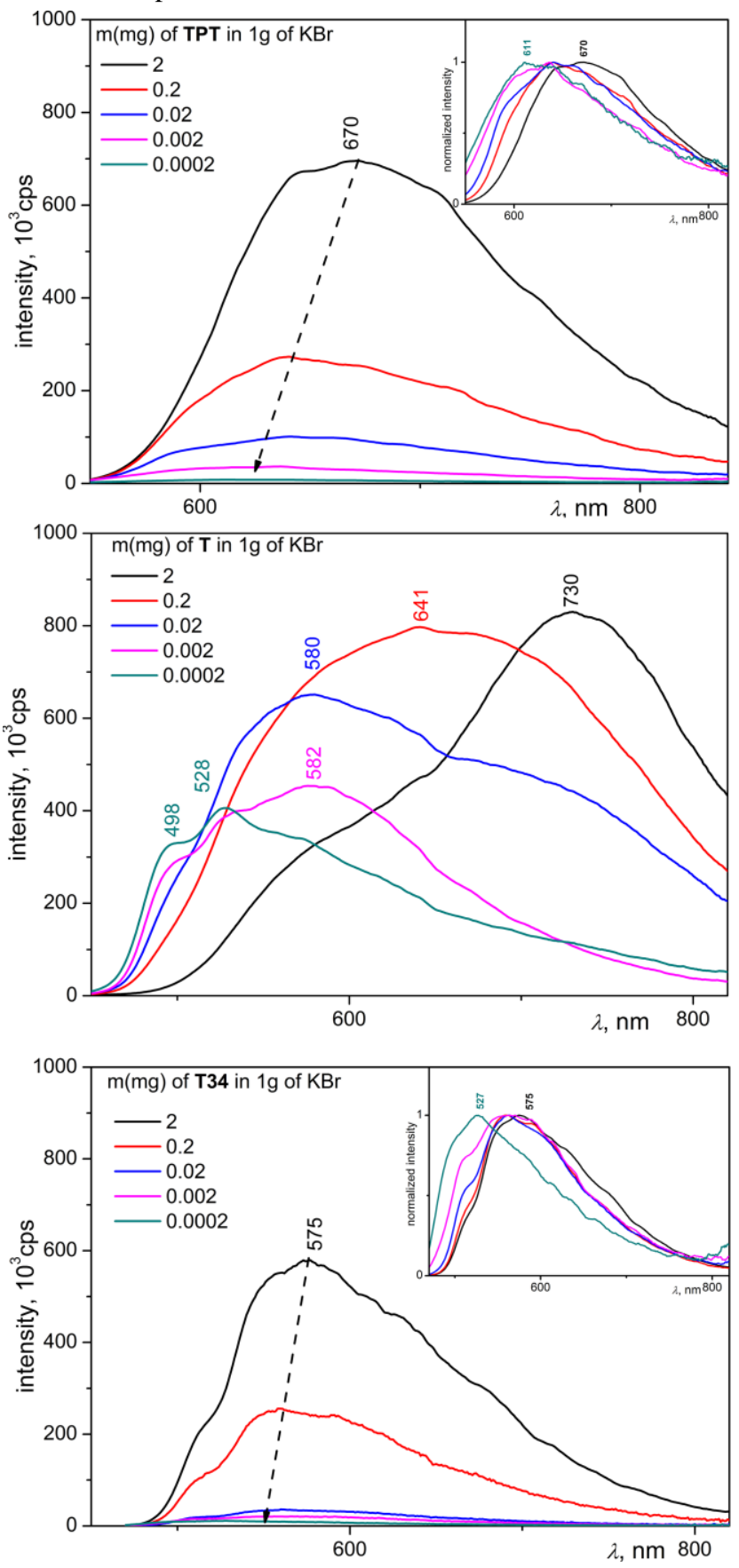

Figure 2: The solid-state luminescence spectra of unimers T, T34 and TPT dispersed at various concentrations in KBr pellets; insets show normalized spectra.
The unimer $\mathbf{T}$ showed a gradual blue-shift of the emission band (up to $-232 \mathrm{~nm}$ ) and a relatively low decrease in the band intensity with decreasing concentration of $\mathbf{T}$ in the matrix (Figure 2). On the contrary, emission maxima of dispersed unimers T34 and TPT showed a small blue-shift (up to $60 \mathrm{~nm}$ ) and rather high intensity decrease upon dilution. These observations are consistent with the hypothesis of regular packing of the $\mathbf{T}$ molecules and poor packing of the TPT and T34 molecules in solid films. For the unimer TPT, the pyramidal geometry of the phosphorus atom precludes a regular cofacial molecular packing in the solid state. ${ }^{34}$ While, for unimer T34, the hexyl side groups can be regarded as the reason for irregular molecular packing.

\section{Optical properties of metallo-supramolecular polymers}

The UV-Vis spectra recorded for the different synthesized MSPs unambiguously show the formation of polymer chain including bis $($ tpy $) \mathrm{M}^{2+}$ units. According to the optical spectral features (see Figure 3 and Table 1), the MSPs derived from TPT can be divided in three categories. The first category concerns the P(TPT/Co), P(TPT/Ni) and P(TPT/Cu) MSPs, which show neither luminescence nor a band of the metal-toligand charge transfer (MLCT) transitions. Only the absorption band of the $\pi-\pi^{*}$ transitions is red-shifted about 27 to $47 \mathrm{~nm}$ (change in band-gap energy, $E_{\mathrm{g}}$, from -0.14 to $0.23 \mathrm{eV})$ in solutions and 6 to $34 \mathrm{~nm}(-0.03$ to $-0.15 \mathrm{eV})$ for films compared to those of unimer TPT. The highest band shift as well as the band broadening is observed for P(TPT/Co), which might be due to the increased contribution of the metal centered d-d transitions, as Kurth et al. have suggested for the cobalt(II) MSP of 1,4-bis(tpy)benzene. ${ }^{48}$ The polymer P(TPT/Zn), representative of the second category, shows luminescence but not the MLCT band. The position as well as intensity of the optical band of P(TPT/Zn) is similar to the bands of the first category of MSPs for the spectra taken from solution. However, the solid state spectra show the mainchain band blue shifted $(-11 \mathrm{~nm}$, i.e., $0.05 \mathrm{eV})$ and attenuated compared to the band of free TPT. Finally, the UV/vis absorption spectrum of $\mathbf{P}(\mathbf{T P T} / \mathbf{F e})$, representative of the third category, shows a very intense band of the MLCT transitions which are typical of $\left[\mathrm{Fe}(t p y)_{2}\right]^{2+}$ species. ${ }^{25,49}$ This band occurs at the wavelength $\lambda_{\mathrm{MLCT}} \cong 625 \mathrm{~nm}$ that is about 20 to $30 \mathrm{~nm}$ red-shifted compared to $\lambda_{\text {MLCT }}$ of Fe-MSPs derived from $\alpha, \omega$ bis(tpy)ter- and quater-thiophenes. ${ }^{23}$ The difference between positions of the main-chain bands of P(TPT/Fe) and free TPT is positive though very small $(+9 \mathrm{~nm})$ for the solution but negative $(-21 \mathrm{~nm})$ for the solid-state spectra. In addition, this band intensity reaches only less than half of the intensity of corresponding bands for the type (i) P(TPT/M)s. These differences in the main-chain band position and intensity can be explained by the shift of some main-chain electronic transitions in $\mathbf{P}(\mathbf{T P T} / \mathbf{F e})$ to the spectral region of the MLCT band (vide infra Raman spectra). 

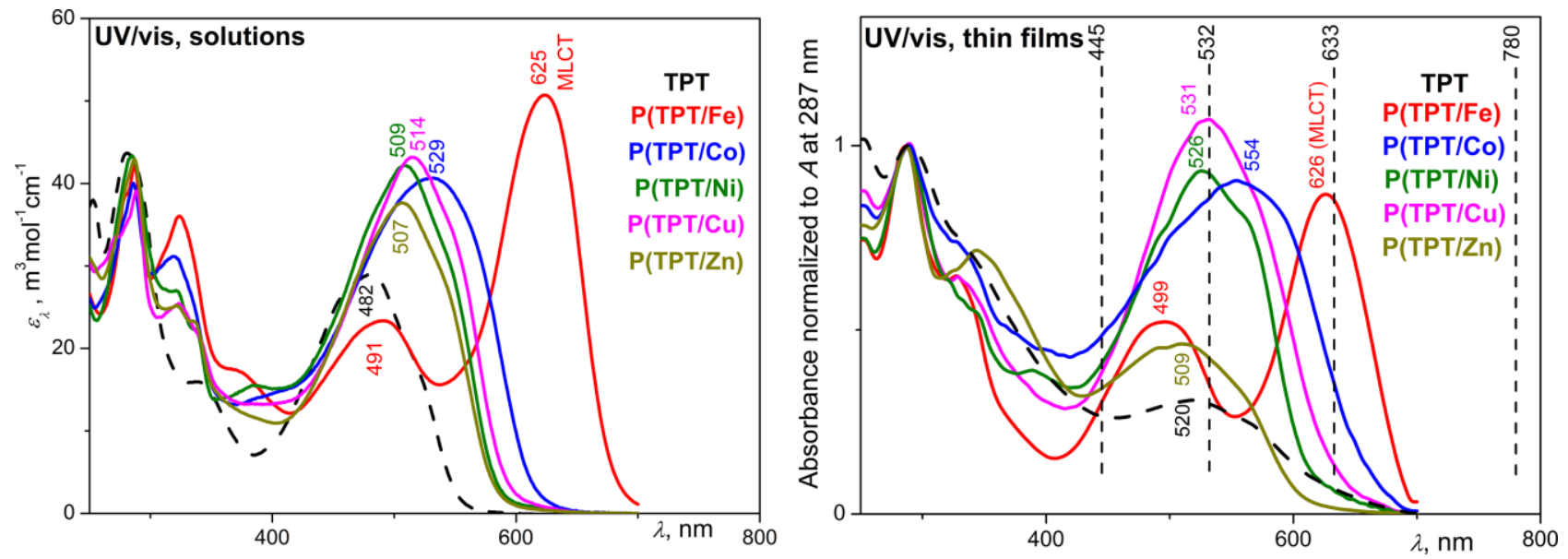

Figure 3: Solution and solid-state UV/vis spectra of unimer TPT and its MSPs. Doted verticals mark excitation wavelengths used in the Raman spectra measurement.

\section{Vibrational spectra of TPT and P(TPT/M)}

Raman spectra can provide valuable information related to the electronic structure of conjugated compounds due to the Raman resonance effect which consists in the selective enhancement of vibrational bands pertaining to groups that absorb light at wavelengths around the excitation wavelength $\lambda_{\text {exc. }}{ }^{50-52}$

For the unimer TPT, only off resonance Raman spectrum (taken with $\lambda_{\text {exc }}=780 \mathrm{~nm}$ which does not match any absorption band, Figures S3 and S4) could be obtained owing to strong luminescence of TPT when using excitations at lower wavelengths $\left(\lambda_{\mathrm{exc}}=435,532\right.$ and $\left.633 \mathrm{~nm}\right)$. The DFT calculated spectrum is in a good agreement with the experimental one (Figure S3). As can be expected for a large molecule composed of different constitutional units, the calculations revealed that all strong spectral bands consist of various stretching and deformation vibrational modes of the units. The spectrum of TPT is dominated by the bands of the thiophene and phosphole units $\left(1400-1500 \mathrm{~cm}^{-1}\right)$ while the bands of tpy endgroups $\left(1520-1600 \mathrm{~cm}^{-1}\right)$ are very weak. Such spectral pattern is typical of the off-resonance spectra of all $\alpha, \omega$ bis(tpy)oligothiophenes. ${ }^{17-21,39}$ Compared to the spectra of $\mathbf{T}$ and T34, the spectrum of TPT shows enhanced bands in the region from 1400 to $1460 \mathrm{~cm}^{-1}$.

Incorporation of the TPT unimer into a metallosupramolecular polymer results in the occurrence of stretching $\left(1610 \mathrm{~cm}^{-1}\right)$ and breathing $\left(\sim 1030 \mathrm{~cm}^{-1}\right)$ Raman bands of coordinated tpy end-groups (that underwent an anti-to-syn conformational transition during coordination to the metal ions, see Fig. 3), and restructuring and slight band shifts assigned to the central block (Figure S3). The off-resonance spectra of $\mathbf{P}(\mathbf{T P T} / \mathbf{M})$ are similar to each other, except for the spectrum of P(TPT/Fe) which shows stronger bands for the stretching $\left(1610 \mathrm{~cm}^{-1}\right)$ and in-plane deformation $\left(1364 \mathrm{~cm}^{-1}\right)$ modes of pyridine rings and the ring-breathing band shifted to 1039 $\mathrm{cm}^{-1}$.

The resonance Raman spectra of P(TPT/Fe) taken with different excitation wavelengths, $\lambda_{\text {exc }}$, each matching different region of the polymer optical spectrum (Figure 2) are shown in Figure S5. The spectrum taken with $\lambda_{\mathrm{exc}}=445 \mathrm{~nm}$ is dominated by the bands of the thiophene and phosphole rings and the tpy end-group bands being almost absent. This proves that the optical band of P(TPT/Fe) at around $445 \mathrm{~nm}$ is largely contributed by electronic transitions within the central blocks.
In contrast, the spectrum taken with $\lambda_{\mathrm{exc}}=532 \mathrm{~nm}$ displays attenuated bands of the central-block rings, strong bands of tpy end-groups and a series of combined bands and overtones in the region above $2000 \mathrm{~cm}^{-1}$. Such spectral pattern is typical of $\mathrm{Fe}^{2+}$ (terpyridine $)_{2}$ species $^{24}$ showing $\lambda_{\mathrm{MLCT}} \cong 550 \mathrm{~nm}^{45,53}$ This proves that the optical absorption of P(TPT/Fe) at $532 \mathrm{~nm}$ is dominantly contributed by the electronic transitions in coordinated tpy groups. ${ }^{53}$ Perhaps the most interesting is the Raman spectrum of P(TPT/Fe) taken with $\lambda_{\mathrm{exc}}=633 \mathrm{~nm}$, matching the maximum of the MLCT band. This spectrum shows strong bands of the tpy groups as well as the central block units. This proves that the electronic transitions from the central blocks of enchained TPT units substantially contribute to the MLCT absorption band. This simultaneously explains why the main UV/vis band of the TPT units enchained in P(TPT/Fe) is very weak and blue-shifted to $500 \mathrm{~nm}$.

The IR spectra of TPT and related polymers are shown in Figure S6, and the experimental and DFT-calculated spectra of TPT are compared in Figure S3. In the IR spectra, the incorporation of TPT into a metallo-polymer is mainly reflected by the occurrence of a strong stretching band from the tpy units at $1610 \mathrm{~cm}^{-1}$ and the development of a strong broad and unresolved band in the region of deformation modes $\left(1200-1000 \mathrm{~cm}^{-1}\right)$; a similar band has not been observed for MSPs derived from $\alpha, \omega$-bis(tpy)oligothiophenes. ${ }^{17-20}$ The IR spectra of MSPs are similar to each other except for the spectrum of P(TPT/Fe), which should be related to the presence of the MLCT transitions in P(TPT/Fe) molecules.

\section{Assembly of polymers in solutions}

Assembly of MSPs from TPT and metal ions $\left(\mathrm{M}^{2+}\right)$ in a chloroform/acetonitrile (1/1 by vol.) solvent mixture was monitored by the UV/vis and luminescence spectroscopies. A set of solutions of the constant TPT concentration of $2 \cdot 10^{-5} \mathrm{M}$ and the ion-to-unimer mole ratio $r=\left[\mathrm{M}^{2+}\right] /[\mathbf{T P T}]$ increasing from 0 to 3 , was prepared for each $\mathrm{M}^{2+} / \mathbf{T P T}$ couple and the solutions were allowed to equilibrate for one day before monitoring their spectra. The UV/vis spectral changes (see Figures S7 and dependences in Figure 4) indicate three stages of assembling, which are usually observed for similar systems. ${ }^{23,24}$ 

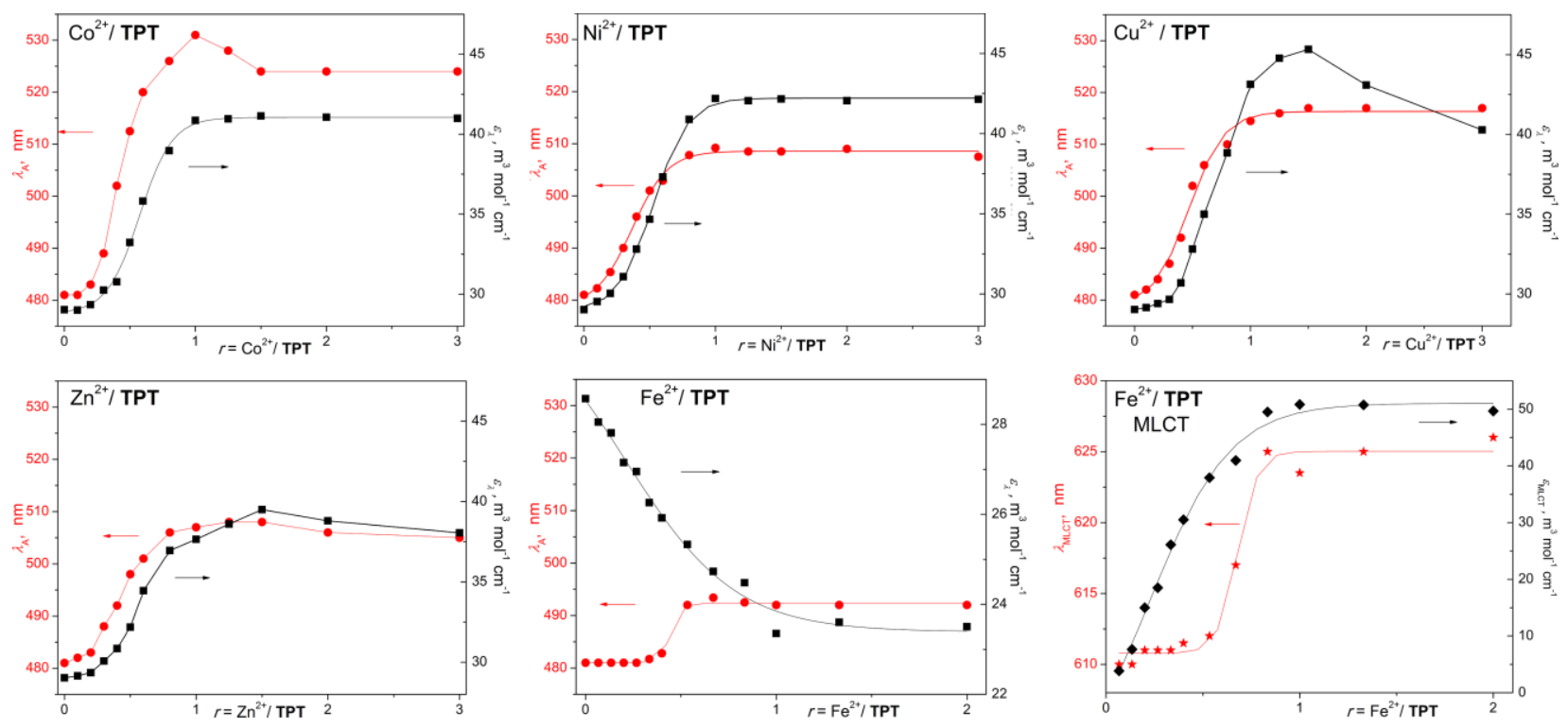

Figure 4: Wavelength $\left(\lambda_{\mathrm{A}}\right)$ and molar absorption coefficient $\left(\varepsilon_{\lambda}\right)$ of the main $\mathrm{UV} / \mathrm{vis}$ band as a function of the ion-to-unimer mole ratio $\left(r=\left[\mathrm{M}^{2+}\right] /[\mathrm{TPT}]\right)$ of the studied systems and $d t$ to for the MLCT band of the Fe $\mathrm{C}^{2+} / \mathrm{TPT}$ system.

The first stage of the MSP assembly appears for $r$ up to ca 0.5 and is characterized by: (i) narrowing and a small red shift (4 to $7 \mathrm{~nm}$ ) of the band of tpy groups (281 nm for free TPT), (ii) red shift (ca $20 \mathrm{~nm}$ ) and enhancement of the absorption band involving transitions centered on the central-block of the TPT units (except for the $\mathrm{Fe}^{2+}$ /TPT system showing a decrease in the intensity), and (iii) appearance of three isosbestic points (IP) at around 300, 415 and $480 \mathrm{~nm}$ for each $\mathrm{M}^{2+} / \mathbf{T P T}$ system. The presence of IPs indicates a direct conversion of the TPT molecules into another defined species which, according to the stoichiometry, should be "butterfly dimer" species TPT-M ${ }^{2+}$ TPT. The second stage of assembly ( $r$ from ca 0.5 to 1 ) is characterized by the continued red shift and intensity increase of the main absorption band, but without occurrence of a clear IP. These features are typical of the prolongation of MSP chains. ${ }^{22-24,54,55}$ The third stage of the assembly $(r>1)$ is characterized by a small change in the spectral pattern that can be attributed to end-capping of MSP chains with metal ions and/or equilibrium dissociation of longer chains to shorter ones induced by superfluous metal ions. ${ }^{42,56,57}$

As indicated above, the $\mathrm{Fe}^{2+} /$ TPT system behaves differently from the other ones: only a small red shift $(+11 \mathrm{~nm})$ and a continuous attenuation of the main optical band is observed if the value of $r$ increases, but together with progressive development of the MLCT band. The main band attenuation can be ascribed to the shift of corresponding electronic transitions to the MLCT band as suggested previously based on the resonance Raman spectra of P(TPT/Fe). Moreover, the MLCT band appears at $612 \mathrm{~nm}$ for dimers while it appears at $625 \mathrm{~nm}$ for mature P(TPT/Fe), which supports this hypothesis.

The luminescence spectra show continuous attenuation of the luminescence with increased ratio $r$ to its total quenching at $r \cong 0.8$. This behavior can be ascribed to the fact that metal ions with an open shell electronic structure usually exhibit strong metal-to-ligand orbital interaction resulting in nonemissive quenching of electronically excited states. ${ }^{58}$ The only exception is the $\mathrm{Zn}^{2+} /$ TPT system for which the luminescence starts to intensify for $r$ values above 0.6 , finally becoming stronger than that of the free unimer (Figure S8) at $r>1$, where end-capping of the Zn-MSP chains take part. This suggests that the luminescence of $\mathbf{P}(\mathbf{T P T} / \mathbf{Z n})$ is mainly contributed by terminal tpy groups capped with $\mathrm{Zn}^{2+}$ ions, the contribution of internal -tpy- $\mathrm{Zn}^{2+}$-tpy- linkages being less important.

Dynamics and degree of polymerization of MSPs in solution

The size exclusion chromatography (SEC) method can provide qualitative information on the constitutional dynamics of MSPs in the solvent used as a mobile phase. ${ }^{24,59}$ If an MSP with fast establishing assembly equilibrium (fast constitutional dynamics) is analyzed by SEC, only a peak for the free unimer is observed due to the fast disassembly of MSP upon multiple dilution of the injected solution inside columns (injected 20 $\mu \mathrm{L}$, elution volume of ca $40 \mathrm{~mL}$ ). However, if an MSP with slow constitutional dynamics is injected, its chains do not completely or substantially dissociate during the SEC analysis and an SEC record resembling the record of an oligomer or polymer is obtained, from which the average degree of polymerization can be calculated. If the SEC device is fitted with a diode-array UV/vis detector, it also provides the spectra of SEC fractions from which the type of chains present in the fractions (dimers, longer or end-capped chains) can be identified or at least ascertained.

For the SEC analysis, one day old solution of TPT $(0.5$ $\mathrm{mM}$ ) and $\mathrm{M}^{2+}$ ions ( $r$ from 0 to 1.3 ) was injected and a chloroform/acetonitrile (1/1 by volume) solvent mixture containing $\mathrm{Bu}_{4} \mathrm{~N}^{+} \mathrm{PF}_{6}^{-}(0.5 \%$ by weight; to suppress aggregation) was used as the mobile phase. Samples with $\mathrm{Co}^{2+}$ ions were not analyzed since they provided opalescent solutions indicating the presence of aggregates. The $\mathrm{Zn}^{2+} / \mathbf{T P T}$ and $\mathrm{Cu}^{2+} / \mathbf{T P T}$ systems provided SEC records showing just a peak of free TPT, which proves fast constitutional dynamics for P(TPT/Zn) and P(TPT/Cu). This agrees with earlier observations made for other MSPs and complexes derived from tpy and $\mathrm{Zn}^{2+}$ or $\mathrm{Cu}^{2+}$ ions. ${ }^{60}$ The systems $\mathrm{Fe}^{2+} /$ TPT and $\mathrm{Ni}^{2+} /$ TPT provided SEC records similar to covalent polymers proving slow constitutional dynamics of these MSPs. Good resolved SEC records were given by the systems with $r \leq 1$ (Figure $\mathbf{5}_{7}$ and S9). The systems with $r \geq 1$ gave poorly resolved rec- 
ords showing a decrease in the elution peak area with increasing value of $r$, which should be ascribed to the retention of chains end-capped with $\mathrm{M}^{2+}$ ions in the SEC columns.

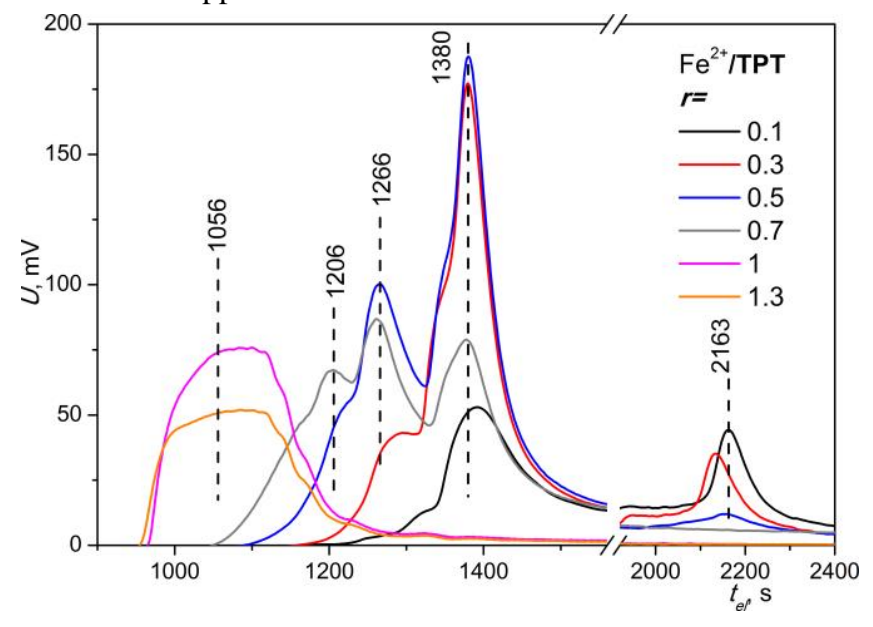

Figure 5. SEC records for different ratios $\mathrm{Fe}^{2+} / \mathrm{TPT}$

The UV/vis spectra of SEC fractions within $\mathrm{Fe}^{2+} /$ TPT system (Figure S10) show a continuous development of the spectral pattern which is typical of long $\mathbf{P}(\mathbf{T P T} / \mathbf{F e})$ chains for the first eluted SEC fractions to the pattern for butterfly dimers in the last fraction. The presence of longer chains in the systems with a stoichiometric lack of $\mathrm{Fe}^{2+}$ ions $(r=0.2$ and 0.5$)$ can be attributed to the transiently locally increased concentration of the ions during mixing their solution with the solution of TPT. Another spectral pattern difference is seen for the SEC fractions with identical elution times but pertaining to systems of different composition ratio $r$ (differences in the fractions of dimers are also shown in Figure S12). In this case the differences can be ascribed to the end-capping of molecules with $\mathrm{Fe}^{2+}$ ions. $^{24}$

The number-average, $\langle X\rangle_{\mathrm{n}}$, and weight-average, $\langle X\rangle_{\mathrm{w}}$, degrees of polymerization of the P(TPT/Fe) chains formed in the solution with $r=1$ have been estimated using the PMMA calibration: $\langle X\rangle_{\mathrm{n}}=4$ and $\langle X\rangle_{\mathrm{w}}=5.7$. These values should be underestimated owing to the retention of polymer higher fractions in the SEC columns. However, a recent time-resolved transient optical absorption study on solutions of $\mathbf{P}(\mathbf{Z n} / \mathbf{T})$ and its derivative $\mathbf{P}(\mathbf{Z n} / \mathbf{T 1 6})$ (with hexyl groups on carbons next to the tpy groups), in which equilibrium fractions of the free unimers $\mathbf{T}$ and $\mathbf{T 1 6}$ have been determined, ${ }^{61}$ gave values of $\langle X\rangle_{\mathrm{n}}=11$ and $\langle X\rangle_{\mathrm{w}}=21$ for $\mathbf{P}(\mathbf{Z n} / \mathbf{T})$ and $\langle X\rangle_{\mathrm{n}}=5$ and $\langle X\rangle_{\mathrm{w}}$ $=9$ for $\mathbf{P}(\mathbf{Z n} / \mathbf{T 1 6})$ calculated using the Carothers equations. The latter values are close to those found for P(TPT/Fe).

\section{CONCLUSIONS}

A novel linear conjugated unimer, TPT, of the bis(tpy) family has been prepared with the aim to verify the theory that a replacement of a thiophene unit with the phosphole unit in a terthiophene central block gives a unimer with significantly decreased band-gap energy. A feasible synthetic path to TPT has been developed and the photophysical properties of TPT have been compared to related bis(tpy)terthiophene unimers. The obtained results confirm that the substitution of thiophene ring with a phosphole ring significantly enhances the delocalization of electrons along the unimer molecule. One small drawback is that P-substituent needed for the good chemical stability of the phosphole ring prevents the regular packing of TPT molecules in films.

Photophysical properties of MSPs assembled from TPT strongly depend on the metal ion linkages. The MSP with $\mathrm{Fe}^{2+}$ ion couplers exhibits a very slow constitutional dynamics, is not luminescent, and shows a strong MLCT band centered at an unusually high wavelength $(625 \mathrm{~nm})$ compared to the FeMSPs derived from unimers with other central blocks. The Raman excitation profile measurements prove that the red arm of the MLCT band of P(TPT/Fe) is significantly contributed with transitions within the central blocks of coordinated TPT units. On the other hand, the MSP with $\mathrm{Zn}^{2+}$ ion couplers exhibits a very fast constitutional dynamics, is luminescent and does not show an MLCT band. The highest luminescence intensity is observed with an excess of $\mathrm{Zn}^{2+}$ ions, which indicates positive effect of end-capping of Zn-MSP chains with $\mathrm{Zn}^{2+}$ ions. The MSPs with $\mathrm{Co}^{2+}, \mathrm{Cu}^{2+}$ and $\mathrm{Ni}^{2+}$ ion couplers exhibit variable dynamics and show neither luminescence nor MLCT band. This conclusively indicates that the quenching of luminescence of MSPs is not related to the formation of the MLCT complex that depletes the electronically excited states.

\section{EXPERIMENTAL}

\section{Materials}

$\operatorname{Bis}\left(1,5\right.$-cyclooctadiene)di- $\mu$-methoxydiiridium(I) $\left([\operatorname{Ir}(\mathrm{OMe})(\mathrm{COD})]_{2}\right)$, 4,4'-di-tert-butyl-2,2'-dipyridyl (dtbpy), 4,4,5,5-tetramethyl-1,3,2dioxaborolane (HBpin), [1,3-bis(2,6-diisopropylphenyl)imidazol-2ylidene](3-chloropyridyl)palladium(II) dichloride (PEPPSI-IPr), sulfur, zinc(II) perchlorate hexahydrate, nickel(II) perchlorate hexahydrate, copper(II) perchlorate hexahydrate, cobalt(II) perchlorate hexahydrate, iron(II) perchlorate hydrate (all Aldrich), potassium carbonate, magnesium sulfate (VWR) and 4'-bromo2,2':6',2"-terpyridine (TCI) were used as received, $P, P$ dichlorophenylphosphine (Aldrich) was distilled trap to trap before use. Tetrahydrofurane (THF) (Aldrich) was dried by $\mathrm{LiAlH}_{4}$ or sodium/benzophenone or using MBraun drying solvents system (SPS800). Toluene (Lachner) was distilled from sodium/benzophenone and water was bubbled with argon before use. Diethylether $\left(\mathrm{Et}_{2} \mathrm{O}\right)$, dichloromethane, pentane (all VWR or Lachner), acetonitrile (ACN), (all Aldrich), hexane, chloroform (Lachner) were used as obtained. 2,5-di(2-thienyl)-1-phenylthiooxophosphole (1) was prepared as described in the literature. ${ }^{36}$

\section{Measurements}

${ }^{1} \mathrm{H}$ and ${ }^{13} \mathrm{C}$ NMR spectra were recorded on a Varian UNITY ${ }^{\text {INOVA } 400}$ or Varian SYSTEM 300 instruments in $\mathrm{CD}_{2} \mathrm{Cl}_{2}$ or $\mathrm{CDCl}_{3}$ and referenced to the solvent signal: $7.25 \mathrm{ppm}\left(\mathrm{CDCl}_{3}\right)$ or $5.32 \mathrm{ppm}$ $\left(\mathrm{CD}_{2} \mathrm{Cl}_{2}\right)$ for ${ }^{1} \mathrm{H}$ and $77.0 \mathrm{ppm}\left(\mathrm{CDCl}_{3}\right)$ or $53.84 \mathrm{ppm}\left(\mathrm{CD}_{2} \mathrm{Cl}_{2}\right)$ for ${ }^{13} \mathrm{C}$ spectra. Coupling constants, $J$ (in $\mathrm{Hz}$ ), were obtained by the firstorder analysis. Infrared spectra were recorded on a Thermo Nicolet 7600 FTIR spectrometer equipped with a Spectra Tech InspectIR Plus microscopic accessory using $\mathrm{KBr}$ diluted samples and diffuse reflectance technique (DRIFT) (128 or more scans at resolution $4 \mathrm{~cm}^{-}$ $\left.{ }^{1}\right)$. Raman spectra were recorded on a DXR Raman microscope (Thermo Scientific) using excitations across the whole visible region $\left(\lambda_{\mathrm{ex}}=445,532,633\right.$ and $\left.780 \mathrm{~nm}\right)$ and usual laser power at the sample 0.1 to $0.4 \mathrm{~mW}$. UV/VIS spectra were recorded on a Shimadzu UV2401PC instrument and photoluminescence spectra on a Fluorolog 322 Jobin Yvon Spex instrument, using four-window quartz cuvette (1 $\mathrm{cm})$ for solutions and quartz glass for thin films. Quantum yields, $\lambda_{\mathrm{F}}$, of photoluminescence were determined by an integration sphere Quanta- $\varphi$ F-3029. KBr pellets for fluorescence measurement were made by grounding specific amount of sample and $\mathrm{KBr}$ using ball mill Vibrator DDR-GM 9458 Narva and then pressed by hydraulic press H62 TRYSTOM. SEC records were obtained using a Spectra Physics Analytical HPLC pump P1000 with two SEC columns: Polymer Labs (Bristol, USA) Mixed-D and Mixed-E. The system was equipped with a Thermo UV6000 DAD detector. A chloro-8 form/acetonitrile ( $1 / 1$ by volume) mixed solvent containing 
$\mathrm{Bu}_{4} \mathrm{~N}^{+} \mathrm{PF}_{6}^{-}(0.5 \%$ by weight; to suppress aggregation $)$ was used as the mobile phase $\left(0.7 \mathrm{~mL} \mathrm{~min}^{-1}\right)$.

\section{Cyclic voltammetry}

Cyclic voltammetry measurements were done on a potentiostat $\mathrm{UM} \mu \mathrm{E}$ Eco-Trend using drop-casted (from dichloromethane) films of compounds deposited on a carbon disc electrode of diameter of $1 \mathrm{~mm}$. $\mathrm{Ag} / \mathrm{AgCl}$ reference electrode, scanning rate of $130 \mathrm{mV} \mathrm{s}^{-1}$ and a solution of $\left(\mathrm{Bu}_{4} \mathrm{~N}\right) \mathrm{PF}_{6}(0.1 \mathrm{M})$ in acetonitrile as the supporting electrolyte were used.

\section{Calculations}

Theoretical calculations were done using the density functional theory (DFT), namely the Becke's three parameter functional with the nonlocal Lee-Yang-Parr correlation functional (B3LYP) with the standard 6-31G(d) basis set as implemented in Gaussian 09 package. ${ }^{62}$ We employed the Becke's three parameter functional with the nonlocal Lee-Yang-Parr correlation functional (B3LYP) with the standard $6-31 \mathrm{G}(\mathrm{d})$ basis set. Electron density and vibrational spectrum of the unimer TPT was calculated for the optimized geometry. The wavenumbers values computed contained systematic errors and were thus scaled by the factor 0.946 for Raman and 0.972 for IR spectra.

\section{Complexation experiments}

In a typical complexation experiment a measured volume of a solution of $\mathrm{Zn}^{2+}$ or $\mathrm{Fe}^{2+}$ perchlorate $\left(2 \times 10^{-3} \mathrm{M}\right)$ in acetonitrile/chloroform (1/1 by vol.) was added into a solution of particular unimer in $\left(2 \times 10^{-5} \mathrm{M}\right)$ in the same solvent. The metal to unimer $\left(\mathrm{M}^{2+} / \mathbf{T P T}\right)$ composition ratio was varied from 0 to 3 . The $\mathrm{UV} / \mathrm{vis}$ absorption and the photoluminescence emission spectra were measured for each solution at room temperature one day after preparation

\section{Synthesis}

1-phenyl-2,5-bis[5-(4,4,5,5-tetramethyl-1,3,2-dioxaboralene-2yl)thiophen-2-yl]thioxophosphole (2).

$[\operatorname{Ir}(\mathrm{OMe})(\mathrm{COD})]_{2}(4 \mathrm{mg}, 3 \mathrm{~mol} \%)$ and dtbpy $(2 \mathrm{mg}, 3 \mathrm{~mol} \%)$ were added to a solution of 1-phenyl-2,5-bis(thiophen-2yl)thioxophosphole $1(82.5 \mathrm{mg} ; 0.2 \mathrm{mmol})$ in dry THF/hexane $(7 / 5$ $\mathrm{mL})$ mixed solvent under argon atmosphere, then HBpin $(0.18 \mathrm{~mL}$, $1.2 \mathrm{mmol}$ ) was added and the reaction mixture kept under stirring at $55^{\circ} \mathrm{C}$ for 30 hours, The mixture was then diluted with dichloromethane $(20 \mathrm{~mL})$ and water $(20 \mathrm{~mL})$, stirred for one hour in an open vessel and, finally, the soluble components were extracted with water $(3 \times 50 \mathrm{~mL})$. The organic phase was dried over magnesium sulfate, filtered off and evaporated to give the product $2(130 \mathrm{mg}$, ca $0.19 \mathrm{mmol}$ ) as a honey-like liquid that was used in the next reaction without further purification (since a significant loss of boronic groups was observed at attempts for chromatographic purification). The compound $\mathbf{2}$ identity has been verified by mass spectroscopy (HRMS) and purity by NMR spectroscopy.

${ }^{1} \mathrm{H}$ NMR $\left(400 \mathrm{MHz}, \mathrm{CD}_{2} \mathrm{Cl}_{2}, \delta / \mathrm{ppm}\right): 7.87(\mathrm{ddd}, J(\mathrm{P}, \mathrm{H})=14.4 \mathrm{~Hz}$, $J(\mathrm{H}, \mathrm{H})=8.4 \mathrm{~Hz}, J(\mathrm{H}, \mathrm{H})=1.6 \mathrm{~Hz} 2 \mathrm{H}, o-\mathrm{H} \mathrm{Ph}), 7.53-7.45(\mathrm{~m}, 2 \mathrm{H}$, $m-\mathrm{H} \mathrm{Ph}), 7.43\left(\mathrm{AB}\right.$ system, $4 \mathrm{H}, J_{\mathrm{AB}}(\mathrm{H}, \mathrm{H})=3.7 \mathrm{~Hz}, v_{\mathrm{AB}}=8.7 \mathrm{~Hz}$, $\left.\mathrm{H}_{\text {thienyl }}\right), 7.38-7.33(\mathrm{~m}, 1 \mathrm{H}, p-\mathrm{H} \mathrm{Ph}), 2.98\left(\mathrm{~m}, 4 \mathrm{H}, \mathrm{C}=\mathrm{CCH}_{2} \mathrm{CH}_{2}\right)$, $1.90\left(\mathrm{~m}, 4 \mathrm{H}, \mathrm{C}=\mathrm{CCH}_{2} \mathrm{CH}_{2}\right), 1.24\left(\mathrm{~s}, 24 \mathrm{H}, \mathrm{CH}_{3}\right)$.

${ }^{31} \mathrm{P}$ NMR (162 MHz, $\left.\mathrm{CD}_{2} \mathrm{Cl}_{2}, \delta / \mathrm{ppm}\right):+51.8$ (s).

${ }^{11} \mathrm{~B}$ NMR (128 MHz, $\left.\mathrm{CD}_{2} \mathrm{Cl}_{2}, \delta / \mathrm{ppm}\right):+22.4$ (s).

${ }^{13} \mathrm{C}$ NMR (101 MHz, $\left.\mathrm{CD}_{2} \mathrm{Cl}_{2}, \delta / \mathrm{ppm}\right): 146.2\left(\mathrm{~d},{ }^{2} J(\mathrm{P}, \mathrm{C})=21.0 \mathrm{~Hz}\right.$, $\mathrm{PC}=\mathrm{C}), 135.3\left(\mathrm{~d},{ }^{2} J(\mathrm{P}, \mathrm{C})=17.4 \mathrm{~Hz}, \mathrm{C}_{\text {thienyl }}\right), 132.6(\mathrm{~d}, J(\mathrm{P}, \mathrm{C})=3.2$ $\left.\mathrm{Hz}, \mathrm{C}_{\mathrm{p}} \mathrm{Ph}\right), 131.2\left(\mathrm{~d}, J(\mathrm{P}, \mathrm{C})=11.8 \mathrm{~Hz}, \mathrm{C}_{\mathrm{o}} \mathrm{Ph}\right), 129.5(\mathrm{~d}, J(\mathrm{P}, \mathrm{C})=$ $75.4 \mathrm{~Hz}, \mathrm{PC}=\mathrm{C}), 129.4\left(\mathrm{~d}, J(\mathrm{P}, \mathrm{C})=12.6 \mathrm{~Hz}, \mathrm{C}_{\mathrm{m}} \mathrm{Ph}\right), 128.9(\mathrm{~d}, J(\mathrm{P}, \mathrm{C})$ $\left.=89.0 \mathrm{~Hz}, \mathrm{C}_{\mathrm{i}} \mathrm{Ph}\right), 128.5\left(\right.$ large $\left.\mathrm{s}, \mathrm{B}-\mathrm{C}_{\text {thienyl }}\right), 127.7\left(\mathrm{~s}, \mathrm{CH}_{\text {thienyl }}\right), 127.4$ (s, $\left.\mathrm{CH}_{\text {thienyl }}\right), 83.6\left(\operatorname{large} \mathrm{s}, \mathrm{CCH}_{3}\right), 29.7(\mathrm{~d}, J(\mathrm{P}, \mathrm{H})=12.4 \mathrm{~Hz}$ $\left.\mathrm{C}=\mathrm{CCH}_{2} \mathrm{CH}_{2}\right), 24.9\left(\mathrm{~s}, \mathrm{CH}_{3}\right), 23.0\left(\mathrm{~s}, \mathrm{C}=\mathrm{CCH}_{2} \mathrm{CH}_{2}\right)$.

FT-IR $\left(\mathrm{cm}^{-1}\right)$ : 3409 (s), 2979 (s), 2929(s), 2860(m), 2040(w), 1719(w), 1618 (m), 1571(w), 1514 (s), 1354(s), 1215(s), 1142(s), 983 $(\mathrm{m}), 957(\mathrm{~m}), 926(\mathrm{~m}), 852(\mathrm{~s}), 746(\mathrm{~m}), 666(\mathrm{~s}), 613(\mathrm{~m}), 578(\mathrm{~m}), 517$ (m), $448(\mathrm{~m}), 419(\mathrm{~m})$
HRMS found $\mathrm{m} / \mathrm{z} 685.1996\left[\mathrm{M}+\mathrm{Na}^{+}\right], \mathrm{C}_{34} \mathrm{H}_{41} \mathrm{~B}_{2} \mathrm{O}_{4} \mathrm{PS}_{3} \mathrm{Na}$ requires 685.1988

1-phenyl-2,5-bis(5-tpy-thiophen-2-yl)thioxophosphole (TPT)

1-Phenyl-2,5-bis[5-(4,4,5,5-tetramethyl-1,3,2-dioxaboralene-2yl)thiophen-2-yl]thioxophosphole) (0.13 g, $0.19 \mathrm{mmol}), \mathrm{Br}$-tpy $(0.12$ $\mathrm{g}, 0.38 \mathrm{mmol}), \mathrm{K}_{2} \mathrm{CO}_{3}(80 \mathrm{mg}, 0.57 \mathrm{mmol})$ and Peppsi-IPr $(13 \mathrm{mg}$, $0.10 \mathrm{~mol} \%$ ), Aliquat 336 (cat.) were placed into a Schlenk flask and then evacuated and flushed with argon. Then toluene $(5 \mathrm{~mL})$ and water $(5 \mathrm{~mL})$ were added, and the reaction mixture was kept at $130^{\circ} \mathrm{C}$ for 18 hours. After cooling to room temperature the reaction mixture was diluted with dichloromethane $(20 \mathrm{~mL})$ and washed with water $(3 \times 20 \mathrm{~mL})$, then dried with magnesium sulfate, filtered off and evaporated. The crude product was purified by column chromatography (aluminum oxide, hexane $/ \mathrm{THF}=3 / 2$ ) giving TPT as a red powder (isolated yield: $24 \mathrm{mg}, 0.03 \mathrm{mmol}, 15 \%$ ). Purity and identity of TPT has been verified by NMR spectroscopy and mass spectrometry.

${ }^{1} \mathrm{H}$ NMR $\left(300 \mathrm{MHz}, \mathrm{CD}_{2} \mathrm{Cl}_{2}, \delta / \mathrm{ppm}\right): 8.73(\mathrm{dd}, J(\mathrm{H}, \mathrm{H})=4.9 \mathrm{~Hz}$, $\left.J(\mathrm{H}, \mathrm{H})=1.0 \mathrm{~Hz}, 4 \mathrm{H}, \mathrm{H}_{\text {pyridyl }}\right), 8.63-8.66\left(\mathrm{~m}, 8 \mathrm{H}, \mathrm{H}_{\text {pyridyl }}\right), 7.98(\mathrm{ddd}$, $J(\mathrm{P}, \mathrm{H})=14.3 \mathrm{~Hz}, J(\mathrm{H}, \mathrm{H})=7.7 \mathrm{~Hz}, J(\mathrm{H}, \mathrm{H})=1.0 \mathrm{~Hz}, 2 \mathrm{H}, o-\mathrm{H} \mathrm{Ph})$, $7.89\left(J(\mathrm{H}, \mathrm{H})=7.5\right.$ and $\left.J(\mathrm{H}, \mathrm{H})=2.00 \mathrm{~Hz}, 4 \mathrm{H}, \mathrm{H}_{\text {pyridyl }}\right), 7.66(\mathrm{~d}$, $\left.J(\mathrm{H}, \mathrm{H})=3.8 \mathrm{~Hz}, 2 \mathrm{H}, \mathrm{H}_{\text {thienyl }}\right), 7.52\left(\mathrm{~d}, J(\mathrm{H}, \mathrm{H})=3.8 \mathrm{~Hz}, 2 \mathrm{H}, \mathrm{H}_{\text {thienyl }}\right)$, $7.38-7.33(\mathrm{~m}, 3 \mathrm{H}, p-\mathrm{H}$ and $m-\mathrm{H} \mathrm{Ph}), 7.35-7.40$ (m, 4H, $\mathrm{H}_{\text {pyridyl }}$ ), $3.11\left(\mathrm{~m}, 4 \mathrm{H}, \mathrm{C}=\mathrm{CCH}_{2},\right), 2.00\left(\mathrm{~m}, 4 \mathrm{H}, \mathrm{C}=\mathrm{CCH}_{2} \mathrm{CH}_{2}\right)$.

${ }^{31} \mathrm{P}$ NMR (121 MHz, $\left.\mathrm{CD}_{2} \mathrm{Cl}_{2}, \delta / \mathrm{ppm}\right):+52.0(\mathrm{~s})$.

${ }^{13} \mathrm{C}$ NMR (101 MHz, $\mathrm{CD}_{2} \mathrm{Cl}_{2}, \delta / \mathrm{ppm}$ ): 156.1 (s, $\left.\mathrm{C}_{\text {pyridyl }}\right), 155.7$ (s, $\left.\mathrm{C}_{\text {pyridyl }}\right), 149.1$ (, $\left.\mathrm{CH}_{\text {pyridyl }}\right) 146.8\left(\mathrm{~d},{ }^{2} J(\mathrm{P}, \mathrm{C})=23.2 \mathrm{~Hz}, \mathrm{PC}=\mathrm{C}\right), 142.8$ $\left(\mathrm{s}, \mathrm{C}_{\text {thienyl }}\right), 142.6\left(\mathrm{~s}, \mathrm{C}_{\text {pyridyl }}\right), 136.8\left(\mathrm{~s}, \mathrm{CH}_{\text {pyridyl }}\right) 136.5\left(\mathrm{~d},{ }^{2} J(\mathrm{P}, \mathrm{C})=\right.$ $\left.17.9 \mathrm{~Hz}, \mathrm{C}_{\text {thienyl }}\right), 132.3\left(\mathrm{~s}, \mathrm{C}_{\mathrm{p}} \mathrm{Ph}\right), 130.6\left(\mathrm{~d}, J(\mathrm{P}, \mathrm{C})=15.6 \mathrm{~Hz}, \mathrm{C}_{\mathrm{o}} \mathrm{Ph}\right)$, $129.1\left(\mathrm{~s}, \mathrm{CH}_{\text {thienyl }}\right), 129.0\left(\mathrm{~d}, J(\mathrm{P}, \mathrm{C})=8.1 \mathrm{~Hz}, \mathrm{C}_{\mathrm{m}} \mathrm{Ph}\right), 128.7(\mathrm{~d}, J(\mathrm{P}, \mathrm{C})$ $=74.6 \mathrm{~Hz}, \mathrm{PC}=\mathrm{C}), 126.0\left(\mathrm{~s}, \mathrm{CH}_{\text {thienyl }}\right), 124.0\left(\mathrm{~s}, \mathrm{CH}_{\text {pyridyl }}\right), 121.1(\mathrm{~s}$, $\left.\mathrm{CH}_{\text {pyridyl }}\right), \quad 116.5$ (s, $\left.\quad \mathrm{CH}_{\text {pyridyl }}\right), \quad 29.5(\mathrm{~d}, \quad J(\mathrm{P}, \mathrm{H})=13.0 \mathrm{~Hz}$ $\left.\mathrm{C}=\mathrm{CCH}_{2} \mathrm{CH}_{2}\right), 22.3\left(\mathrm{~s}, \mathrm{C}=\mathrm{CCH}_{2} \mathrm{CH}_{2}\right) . \mathrm{C}_{\mathrm{i}}$ Ph not observed.

FT-IR $\left(\mathrm{cm}^{-1}\right)$ : 3432 (w), 3030 (w), 3051 (w), 3014 (w), 2946 (w), 2867(w), 1598(s), 1582(s), 1567 (s), 1547 (m), 1466 (m), 1449 (s), 1399(s), 1363(w), 1290(w), $1267(\mathrm{w}), 1224(\mathrm{w}), 1145(\mathrm{w}), 1097(\mathrm{~m})$, $1075(\mathrm{w}), 1042(\mathrm{w}), 1011(\mathrm{~s}), 990(\mathrm{w}) .878(\mathrm{w}), 850(\mathrm{w}), 788(\mathrm{~s}), 775$ (w), $745(\mathrm{~m}), 731(\mathrm{~m}), 718(\mathrm{w}) 691(\mathrm{w}), 678(\mathrm{w}), 665(\mathrm{~m}), 635(\mathrm{w})$, $623(w), 608(w), 555(w), 533(w), 499(w), 468(w)$

HRMS found $\mathrm{m} / \mathrm{z} 873.2059\left[\mathrm{M}+\mathrm{H}^{+}\right], \quad \mathrm{C}_{52} \mathrm{H}_{38} \mathrm{~N}_{6} \mathrm{PS}_{3}$ requires 873.205773

\section{ASSOCIATED CONTENT}

\section{Supporting Information}

Supporting information contains: overall scheme of synthesis, electronic density contours obtained by DFT calculations, Raman and IR spectra, fluorescence spectra in thin films, spectral changes accompanying self-assembly of metallo-supramolecular polymers, SEC records for $\mathbf{P}(\mathbf{N i} / \mathbf{T P T})$ and UV/vis DAD spectra of SEC fractions of $\mathrm{Fe}^{2+} /$ TPT system, cyclic voltammetry of unimer TPT, ${ }^{1} \mathrm{H}$ and ${ }^{13} \mathrm{C}$ NMR spectra of newly synthesized compounds (PDF). The geometry optimized coordinates of DFT calculations are available as supplemental txt file.

The Supporting Information is available free of charge on the ACS Publications website.

\section{AUTHOR INFORMATION}

\section{Corresponding Author}

Muriel Hissler : murriel.hissler@univ-rennes1.fr Jiri Vohlidal : jiri.vohlidal@ natur.cuni.cz

The authors declare no competing financial interests

\section{ACKNOWLEDGMENT}

This work was supported by the Czech Science Foundation9 (P108/12/1143), the Grant Agency of Charles University (pro- 
ject 837013) and the COST Action CM1302 (SIPS) European Network on Smart Inorganic Polymers. Dr. I. Šloufová (Charles University in Prague) is greatly acknowledged for IR and Raman spectra measurement. Access to computing and storage facilities owned by parties and projects contributing to the National Grid Infrastructure MetaCentrum, provided under the program "Projects of Large Research, Development, and Innovations Infrastructures" (CESNET LM2015042), is greatly appreciated.

M. Hissler acknowledges support from the Ministère de la Recherche et de l'Enseignement Supérieur, the CNRS, the Région Bretagne.

\section{REFERENCES}

(1) Grimsdale, A. C.; Chan, K. L.; Martin, R. E.; Jokisz, P. G.; Holmes, A. B. Chem. Rev. 2009, 109, 897-1091.

(2) Moliton, A.; Hiorns, R. C. Polym. Int. 2004, 53, 1397-1412.

(3) Cheng, Y.-J.; Yang, S.-H.; Hsu, C.-S. Chem. Rev. 2009, 109, 5868-5923.

(4) Whittell, G. R.; Hager, M. D.; Schubert, U. S.; Manners, I. Nat. Mater. 2011, 10 (3), 176-188.

(5) Winter, A.; Schubert, U. S. Chem. Soc. Rev. 2016, 45, 53115357.

(6) Bernhard, S.; Goldsmith, J. I.; Takada, K.; Abruna, H. D. Inorg. Chem. 2003, 42 (14), 4389-4393.

(7) Lehn, J.-M.; Lehn, J.-M. Chem. Soc. Rev. 2007, 36, 151-160.

(8) Kumpfer, J. R.; Rowan, S. J. J. Am. Chem. Soc. 2011, 133 (32), 12866-12874.

(9) Lehn, J. M. Prog. Polym. Sci 2005, 30, 814-831.

(10) Ciferri, A. Macromol. Rapid Commun. 2002, 23 (9), 511-529.

(11) Hofmeier, H.; Schubert, U. S. Chem. Soc. Rev. 2004, 33 (6), 373-399.

(12) Wild, A.; Winter, A.; Schlütter, F.; Schubert, U. S. Chem. Soc. Rev. 2011, 40 (3), 1459-1511.

(13) Kelch, S.; Rehahn, M. Macromolecules 1999, 32, 5818-5828.

(14) Schmelz, O.; Rehahn, M. e-Polym. 2002, No. 47, 1-29.

(15) Fu, S. H.; Higuchi, M.; Kurth, D. G. J. Am. Chem. Soc. 2008, 130 (6), 2073-2081.

(16) Wild, A.; Schlütter, F.; Pavlov, G. M.; Friebe, C.; Festag, G.; Winter, A.; Hager, M. D.; Cimrová, V.; Schubert, U. S. Macromol. Rapid Commun. 2010, 31 (9-10), 868-874.

(17) Yuan, S. C.; Chen, H. B.; Zhang, Y.; Pei, J. Org. Lett. 2006, 8 (25), 5701-5704.

(18) Schlütter, F.; Wild, A.; Winter, A.; Hager, M. D.; Baumgaertel, A.; Friebe, C.; Schubert, U. S. Macromolecules 2010, 43 (6), 2759-2771.

(19) Hjelm, J.; Constable, E. C.; Figgemeier, E.; Hagfeldt, A.; Handel, R.; Housecroft, C. E.; Mukhtar, E.; Schofield, E. Chem. Commun. 2002, No. 3, 284-285.

(20) Han, F. S.; Higuchi, M.; Kurth, D. G. Tetrahedron 2008, 64 (38), 9108-9116.

(21) Svoboda, J.; Štenclová, P.; Uhlík, F.; Zedník, J.; Vohlídal, J. Tetrahedron 2011, 67 (1), 75-79.

(22) Bláhová, P.; Zedník, J.; Šloufová, I.; Vohlídal, J.; Svoboda, J. Soft Mater. 2014, 12, 214-229.

(23) Štenclová, P.; Šichová, K.; Šloufová, I.; Zedník, J.; Svoboda, J.; Vohlídal, J.; Svoboda, J. Dalton Trans. 2016, 45, 1208-1224.

(24) Štenclová-Bláhová, P.; Svoboda, J.; Šloufová, I.; Vohlídal, J. Phys. Chem. Chem. Phys. 2015, 17 (20), 13743-13756.

(25) Schubert U. S, Hofmeier H., N. G. R. Modern Terpyridine Chemistry; Wiley-VCH, 2006.

(26) Salzner, U.; Lagowski, J. B.; Pickup, P. G.; Poirier, R. a. Synth. Met. 1998, 96, 177-189.

(27) Fave, C.; Hissler, M.; Kárpati, T.; Rault-Berthelot, J.; Deborde, V.; Toupet, L.; Nyulászi, L.; Réau, R. J. Am. Chem. Soc. 2004,
126 (19), 6058-6063.

(28) Matano, Y.; Imahori, H. Org. Biomol. Chem. 2009, 7 (7), 1258 1271.

(29) Sebastian, M.; Hissler, M.; Fave, C.; Rault-Berthelot, J.; Odin, C.; Réau, R. Angew. Chem. Int. Ed. 2006, 45 (37), 6152-6155.

(30) Hobbs, M. G.; Baumgartner, T. Eur. J. Inorg. Chem. 2007, 3611-3628.

(31) Hay, C.; Fave, C.; Hissler, M.; Rault-Berthelot, J.; Réau, R. Org. Lett. 2003, 5 (19), 3467-3470.

(32) Hay, C.; Fischmeister, C.; Hissler, M.; Toupet, L.; Réau, R. Angew. Chem. Int. Ed. 2000, 39 (10), 1812-1815.

Fave, C.; Cho, T. Y.; Hissler, M.; Chen, C. W.; Luh, T. Y.; Wu, C. C.; Réau, R. J. Am. Chem. Soc. 2003, 125 (31), 9254-9255.

Su, H.-C.; Fadhel, O.; Yang, C.-J.; Cho, T.-Y.; Fave, C.; Hissler, M.; Wu, C.-C.; Reau, R. J. Am. Chem. Soc. 2006, 128 (3), 983-995.

Hissler, M.; Lescop, C.; Réau, R. J. Organomet. Chem. 2005, 690 (10), 2482-2487.

Hay, C.; Hissler, M.; Fischmeister, C.; Rault-Berthelot, J.; Toupet, L.; Nyulászi, L.; Réau, R. Chem. Eur. J. 2001, 7 (19), $4222-4236$.

Crassous, J.; Réau, R. Dalton Trans. 2008, No. 48, 6865-6876.

Matano, Y.; Miyajima, T.; Ochi, N.; Nakabuchi, T.; Shiro, M.; Nakao, Y.; Sakaki, S.; Imahori, H. J. Am. Chem. Soc. 2008, 130 (3), 990-1002.

Fadhel, O.; Gras, M.; Lemaitre, N.; Deborde, V.; Hissler, M.; Geffroy, B.; Réau, R. Adv. Mater. 2009, 21, 1261-1265.

Crassous, J.; Lescop, C.; Reau, R. Phosphorus Compounds; Peruzzini, M., Gonsalvi, L., Eds.; Catalysis by Metal Complexes; Springer Netherlands: Dordrecht, 2011; Vol. 37.

Fadhel, O.; Szieberth, D.; Deborde, V.; Lescop, C.; Nyulászi, L.; Hissler, M.; Réau, R. Chem. - A Eur. J. 2009, 15 (19), 49144924.

Bai, D. R.; Romero-Nieto, C.; Baumgartner, T. Dalton Trans. 2010, 39 (5), 1250-1260.

Chotana, G. A.; Kallepalli, V. A.; Maleczka, R. E.; Smith, M. R. Tetrahedron 2008, 64 (26), 6103-6114.

Nyulászi, L.; Hollóczki, O.; Lescop, C.; Hissler, M.; Réau, R. Org. Biomol. Chem. 2006, 4 (6), 996-998.

Vitvarová, T.; Zedník, J.; Bláha, M.; Vohlídal, J.; Svoboda, J. Eur. J. Inorg. Chem. 2012, No. 24, 3866-3874.

Yang, A. P.; Kuroda, M.; Shiraishi, Y.; Kobayashi, T. J. Chem. Phys. 1998, 109 (19), 8442-8450.

Sauer, M.; Hofkens, J.; Enderlein, J. Basic Principles of Fluorescence Spectroscopy, Wiley-VCH.; 2011.

Kurth, D. G.; Schütte, M.; Wen, J. Colloids Surfaces A Physicochem. Eng. Asp. 2002, 198-200, 633-643.

Bochet, C. G.; Piguet, C.; Williams, A. F. Helv. Chim. Acta 1993, 76 (1), 372-384.

Zerbi, G.; Gussoni, M.; Castiglioni, C. In Conjugated polymers; Brédas, J. L., Silbey, R., Eds.; Kluwer Academic Publishers: Dordrecht, 1991; p 435.

Gussoni, M.; Castiglioni, C.; Zerbi, G. In Spectroscopy of Advanced materials; Clark, R. J. H., Hester, R. E., Eds.; Wiley: New York, 1991; p 251.

Bláha, M.; Riesová, M.; Zedník, J.; Anžlovar, A.; Žigon, M.; Vohlídal, J. Synth. Met. 2011, 161 (13), 1217-1225.

Šloufová, I.; Vlčková, B.; Procházka, M.; Svoboda, J.; Vohlídal, J. J. Raman Spectrosc. 2014, 45, 338-348.

Dobrawa, R.; Würthner, F. J. Polym. Sci. Part A Polym. Chem. 2005, 43 (21), 4981-4995.

Gallina, M. E.; Bergamini, G.; Di Motta, S.; Sakamoto, J.; Negri, F.; Ceroni, P. Photochem. Photobiol. Sci. 2014, 13 (7), 997-1004.

Dobrawa, R.; Lysetska, M.; Ballester, P.; Grüne, M.; Würthner, F. Macromolecules 2005, 38 (4), 1315-1325.

Stepanenko, V.; Stocker, M.; Müller, P.; Büchner, M.;
10 
Würthner, F. J. Mater. Chem. 2009, 19 (37), 6816-6826.

(58) Zhang, M.; Lu, P.; Ma, Y.; Shen, J. J. Phys. Chem. B 2003, 107, 6535-6538.

(59) Chiper, M.; Meier, M. a R.; Kranenburg, J. M.; Schubert, U. S. Macromol. Chem. Phys. 2007, 208 (7), 679-689.

(60) Hogg, R.; Wilkins, R. G. J. Chem. Soc. 1962, 341-350.

(61) Rais, D.; Menšík, M.; Štenclová-Bláhová, P.; Svoboda, J.; Vohlídal, J.; Pfleger, J. J. Phys. Chem. A 2015, 119 (24), 62036214.

(62) Frisch, M. J.; Trucks, G. W.; Schlegel, H. B.; Scuseria, G. E.; Robb, M. A.; Cheeseman, J. R.; Scalmani, G.; Barone, V.; Mennucci, B.; Petersson, G. A.; Nakatsuji, H.; Caricato, M.; Li, X.; Hratchian, H. P.; Izmaylov, A. F.; Bloino, J.; Zheng, G.; Sonnenberg, J. L.; Hada, M.; Ehara, M.; Toyota, K.; Fukuda, R.; Hasegawa, J.; Ishida, M.; Nakajima, T.; Honda, Y.; Kitao, O.; Nakai, H.; Vreven, T.; Montgomery, J. A.; Peralta, J. E.; Ogliaro, F.; Bearpark, M.; Heyd, J. J.; Brothers, E.; Kudin, K. N.; Staroverov, V. N.; Kobayashi, R.; Normand, J.; Raghavachari, K.; Rendell, A.; Burant, J. C.; Iyengar, S. S.; Tomasi, J.; Cossi, M.; Rega, N.; Millam, J. M.; Klene, M.; Knox, J. E.; Cross, J. B.; Bakken, V.; Adamo, C.; Jaramillo, J.; Gomperts, R.; Stratmann, R. E.; Yazyev, O.; Austin, A. J.; Cammi, R.; Pomelli, C.; Ochterski, J. W.; Martin, R. L.; Morokuma, K.; Zakrzewski, V. G.; Voth, G. A.; Salvador, P.; Dannenberg, J. J.; Dapprich, S.; Daniels, A. D.; Farkas, Ö.; Foresman, J. B.; Ortiz, J. V.; Cioslowski, J.; Fox, D. J. Gaussian, Inc., Wallingford CT 2009. 
Table of contents

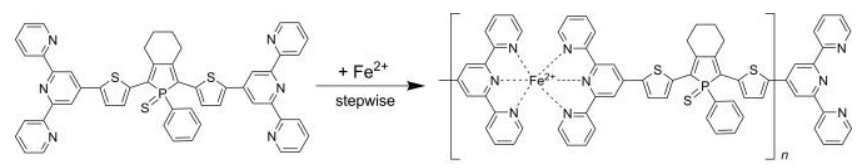

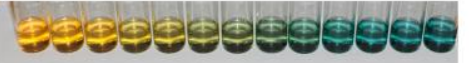

